\title{
PAISAGEM E TURISMO: QUALIDADE VISUAL DA PRAIA DO CUMBUCO - CAUCAIA/CE
}

\author{
LANDSCAPE AND TOURISM: VISUAL QUALITY OF CUMBUCO BEACH - CAUCAIA/CE
}

\author{
Anderson da Silva Marinho ${ }^{1}$ \\ Laura Mary Marques Fernandes ${ }^{2}$ \\ Edson Vicente da Silva ${ }^{3}$ \\ Francisco Davy Braz Rabelo4
}

\begin{abstract}
1 Licenciado em Geografia, Universidade Federal do Ceará. E-mail: asm.jems100@gmail.com
2 Doutora em Geografia, Universidade Estadual do Ceará. E-mail: lauralucas66@hotmail.com

3 Doutor e Docente do Curso de Geografia, Universidade Federal do Ceará. E-mail: cacauceara@gmail.com

4 Mestre em Geografia, Universidade Federal do Ceará. E-mail: davyrabelo@yahoo.com.br
\end{abstract}

RESUMO: Este artigo objetiva analisar a qualidade visual da paisagem da praia do Cumbuco, no município de Caucaia/CE, Região Metropolitana de Fortaleza. Como suporte teórico utilizou-se teóricos da geoecologia das paisagens. Os principais resultados foram: variedade de elementos naturais, diversidade e naturalidade média às paisagens, presença de médios e grandes indicadores detratores, como: casas de veraneio, barracas, restaurantes, hotéis e condomínios. Como constatação inferiu-se que a qualidade visual é média, principalmente na área de maior concentração de turistas significando que a paisagem, motivadora dos fluxos turísticos, transformou-se perdendo características próprias e adquirindo novas feições.

Palavras-chave: Paisagem. Turismo. Qualidade Visual.

ABSTRACT: This article aims to analyze the visual quality of the Cumbuco beach landscape, in the municipality of Caucaia / CE, Metropolitan Region of Fortaleza. Theoretical support was used for geoecology theorists. The main results were variety of natural elements, diversity and average naturalness to the landscape, presence of medium and large indicators of tractors, such as summer houses, tents, restaurants, hotels and condominiums. As a result, it was inferred that the visual quality is average, mainly in the area of greater concentration of tourists, meaning that the landscape, which is a motivator of tourist flows, has lost its own characteristics and acquired new features.

Keywords: Landscape. Tourism. Visual Quality.

Sumário: Introdução - 1 Apresentação Socioambiental da Praia do Cumbuco - 2 Geoecologia da Paisagem e Turismo - 3 Percurso Metodológico - 4 Resultados e Discussões sobre a Análise da Qualidade Visual do Cumbuco - Considerações Finais - Referências

\section{INTRODUÇÃO}

A paisagem constitui substrato importante para o desenvolvimento das atividades de lazer e turismo. Os cartões postais e as páginas da internet demonstram o uso da paisagem como elemento de divulgação dos lugares para atração de visitantes. Apesar da conservação do ambiente ser necessária, inclusive para manter a atratividade dos destinos turísticos, verifica-se que o desenvolvimento do turismo transforma as relações socioespaciais e muda as paisagens naturais e culturais dos territórios, por exemplo, com a implantação dos fixos necessários para receber visitantes como hotéis e pousadas. A identificação e análise da intensidade desses impactos é fundamental para compreender a ação da sociedade sobre os geoecossistemas. Nesse sentido, estudos geográficos sobre as consequências do turismo nas paisagens concretizam a aproximação entre a geografia e o turismo nas pesquisas acadêmicas.

Este artigo tem como objetivo analisar a qualidade visual da paisagem da praia do Cumbuco, localizada no município de Caucaia-CE na Região Metropolitana de Fortaleza e contribuir para valorização e 
preservação paisagística natural e cultural do lugar. O principal apelo da divulgação do estado do Ceará no turismo recai nas paisagens litorâneas e essa área apresenta paisagem de relevante valor natural, cultural e turístico destacando-se o campo de dunas, lagoas interdunares, vegetação costeira e a faixa de praia e póspraia.

É relevante estudar o uso dessas paisagens que constitui um conjunto de elementos naturais e sociais como recurso para o turismo e verificar como o ambiente foi apropriado por essa prática social. Para tanto, identificaram-se as formas de uso e ocupação da planície litorânea do município, especificamente da faixa de praia e pós-praia. A paisagem é definida como o que a visão alcança e seus diferentes fatores como clima, temperatura e a cultura do lugar proporcionam a totalidade visível. Esses fatores e a proximidade com a capital tornaram Cumbuco um dos lugares mais visitados do litoral à oeste de Fortaleza e um dos principais destinos de lazer e turismo do estado do Ceará.

A abordagem interdisciplinar da geografia e de turismo aprofunda o conhecimento da realidade, pois supera a especialização buscando o entendimento do objeto estudado na sua totalidade. No entanto, o exerć́cio da interdisciplinaridade apresenta algumas dificuldades metodológicas e conceituais, por isso estabeleceu-se como suporte teórico desta pesquisa, a geoecologia das paisagens que proporciona uma visão complexa e sistêmica para o levantamento abrangente da área de estudo e uma adaptação dos indicadores da qualidade visual propostos por Pires (2005), para avaliação de paisagens turísticas. O uso de indicadores e a avaliação da qualidade visual das paisagens são parâmetros que possibilitam propor medidas mitigadoras e compensatórias no contexto do planejamento ambiental.

\section{APRESENTAÇÃO SOCIOAMBIENTAL DA PRAIA DO CUMBUCO}

A praia do Cumbuco está localizada no município de Caucaia, que faz parte da Região Metropolitana de Fortaleza e possui população estimada para 2019 de 361.400 habitantes, a maior população municipal depois de Fortaleza segundo o Instituto Brasileiro de Geografia e Estatística (IBGE, 2019). Localizado à oeste de Fortaleza, o litoral desse município inicia-se na foz do rio Ceará, na divisa com Fortaleza, indo até a zona portuária do Pecém. Incorpora, além de Cumbuco, distante aproximadamente 20km da capital, as praias de Dois Coqueiros, Iparana, Pacheco, Icarái, Barra Nova, Tabuba e a Barra do Cauípe.

A Figura 1, apresenta a localização geográfica da praia do Cumbuco. A área de estudo compreende um trecho de aproximadamente $8 \mathrm{~km}$, a partir da margem direita do rio Cauípe na direção oeste-leste. A faixa observada para análise da paisagem está compreendida entre a zona de estirâncio e a área de pós-praia. 
Figura 1 - Mapa de localização da Praia do Cumbuco

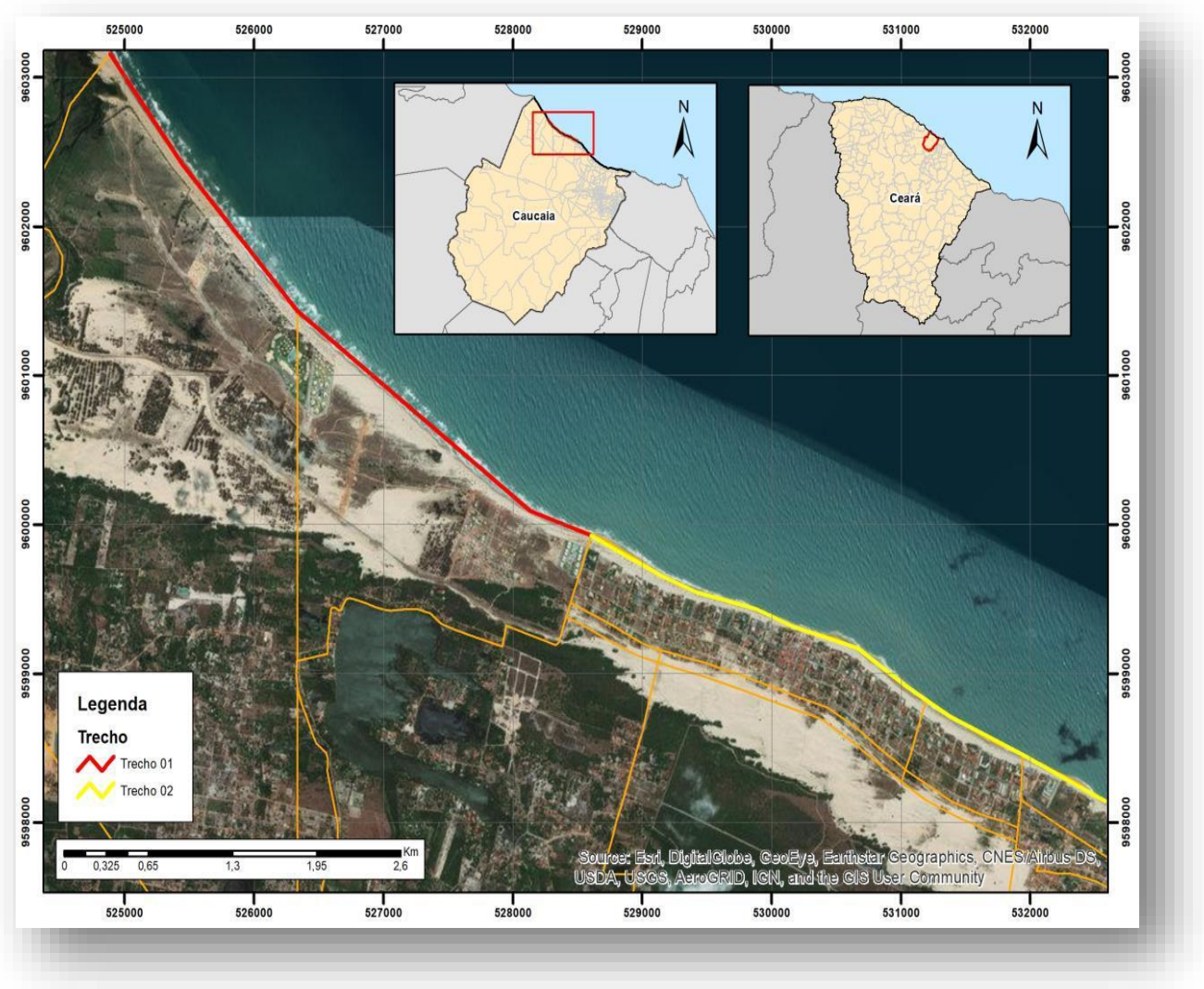

Fonte: Elaborado pelos autores (2018).

Instituído legalmente em 1759, o município de Caucaia possui dimensão territorial de 1.227,931 km². O índice de desenvolvimento Humano (IDH) municipal, 2016 foi de 45,12, colocando o município na $12^{\mathrm{a}}$ posição no ranking estadual (IPECE, 2017). Caucaia em seu conjunto municipal possui o $3^{\circ}$ maior PIB do Estado do Ceará e o setor que mais impacta a economia é o de serviços com $67,76 \%$ conforme dados de 2015. A agropecuária tem participação de 1,07\% e a indústria de 31,17\% no Produto Interno Bruto - PIB do município (IPECE, 2017).

A intensificação do processo de ocupação litorânea de Caucaia foi iniciada nos anos 1950, com a construção da Colônia de Férias do Serviço Social do Comércio (SESC) em Iparana. A zona litorânea municipal até os anos 1950, caracterizava-se pela presença das vilas de pescadores nas praias de Cumbuco, Icaraí e Tabuba. Entre os anos 1950 e1980 a ocupação é voltada para o veraneio e o turismo. A partir dos anos 1980, acontece a ocupação turística, em Tabuba e Cumbuco, com empreendimentos turísticos de diferentes padrões (ARAÚJO e PEREIRA, 2011 e SOUZA, 2013).

Entre as décadas de 1950 e 1980 predominam empreendimentos menos sofisticados, porém a partir dos anos 1980 os fluxos turísticos se diversificam de público local, regional e estadual para estadual, nacional e internacional, influenciando os padrões de meios de hospedagem com a oferta de hotéis mais sofisticados e resorts (ARAUJO; PEREIRA, 2011). Nos anos 1990 e 2000, surgem com mais evidência os condomínios fechados de segundas residências e os condomínios resorts [...] (SOUZA, 2013, p.124). A partir do início dos anos 2000 são implantados condomínios resorts, entre eles o Ocean View, Cumbuco Dream Village, Cumbuco Dream Beach, Cumbuco Dream Sun, o VG Sun Cumbuco e o Wai Wai Cumbuco Eco Residence.

A ocupação urbana do litoral de Caucaia ocorreu sobre os campos de dunas. Dessa forma, nos anos 2010 a praia do Cumbuco apresentava diferentes formas de ocupação. Sob a influência do lazer, do turismo e da especulação imobiliária diversos empreendimentos foram instalados podendo-se verificar o efeito 
territorial na paisagem dessa área que até os anos 1980 era uma vila de pescadores, oriunda do território de uma propriedade fundiária.

No período entre 2004 e 2011 o fluxo internacional de turistas para o município de Caucaia aumentou de 32.493 para 79.576, a renda gerada pelo turismo passou de $\mathrm{R} \$ 96,20$ (noventa e seis reais e vinte centavos) para $\mathrm{R} \$ 270,30$ (duzentos e setenta reais e trinta centavos) por turista/dia e a demanda hoteleira de 118.499 para 270.858 por ano. A oferta da rede hoteleira passou de 560 Unidades Habitacionais, ou seja, apartamentos, para 1.429 em dezembro de 2004 (PREFEITURA MUNICIPAL DE CAUCAIA, 2018).

Esses números expressam a ampliação das atividades relacionadas ao turismo e consequentemente o acréscimo e a intensificação de impactos positivos e negativos. A natureza desses impactos atinge de diferentes formas residentes e agentes públicos e privados ligados ao turismo. Como afirma Cruz (2002, p.9), "o consumo dos territórios pelo turismo envolve o consumo de um conjunto, indissociável, de bens e serviços que compõem o fazer turístico".

A paisagem do Cumbuco é composta por campo de dunas e plantio de coqueiros e apresenta trechos na faixa de pós-praia ocupados por casas de veraneio, pousadas, hotéis e barracas. Além da praia, o lugar é conhecido pelo passeio de buggy pelas dunas. Nesse território convivem a atividade tradicional da pesca, tanto em jangadas quanto a pesca em rede e, nos últimos anos as práticas de turismo e atividades esportivas de kitesurf que fizeram proliferar escolas e pousadas para esse o público. Com essa prática esportiva, possível devido às características naturais da área, novos hábitos foram surgindo principalmente para o público jovem.

\section{GEOECOLOGIA DA PAISAGEM E TURISMO}

A identificação e o mapeamento das unidades de paisagem aprofundam o conhecimento sobre o território em análise, pois demonstram a síntese que reúne as relações entre esses elementos, bem como fornecem subsídios importantes para a intervenção na área estudada. Dessa forma, a geoecologia da paisagem contribui na análise e diagnóstico das bases naturais de determinado espaço geográfico, fornece fundamentos teórico-metodológicos para a implementação de ações de planejamento e gestão ambiental e subsidia a implantação de modelos de uso e ocupação voltados à sustentabilidade socioambiental (RODRIGUEZ; SILVA e LEAL, 2011).

As transformações dos territórios e a compreensão sobre paisagem não se resumem ao que se pode identificar por meio dos elementos tangíveis, pois incluem o cotidiano e os modos de ser e fazer das pessoas, porém a visão é preponderante no estudo da paisagem e no turismo está ligada diretamente ao apelo na atração de visitantes para os lugares. Nesta pesquisa, destacam-se os atrativos naturais e a ação da sociedade na implantação das atividades de lazer e de turismo.

A geoecologia da paisagem utiliza como categorias analíticas o espaço ou a paisagem natural, espaço geográfico, paisagem cultural e território. A praia do Cumbuco constitui-se em um território composto por "um conjunto de espaços e paisagens geográficas e sistemas naturais, econômicos e sociais [...] delimitada por fatores econômicos e políticos” (RODRIGUEZ; SILVA e LEAL, 2011). É um espaço de poder e gestão onde ocorrem práticas tradicionais e modernas como a pesca e o turismo que transformam a paisagem natural e a paisagem cultural. A atividade da pesca ainda pode ser identificada na área, o que significa a resistência dos que fazem essa atividade tradicional.Entre os sistemas ambientais do município de Caucaia destacam-se neste trabalho a planície litorânea e a planície lacustre. O Quadro 1 apresenta as principais características dessas unidades geoecológicas. 
Quadro 1 - Unidades geoecológicas da Praia do Cumbuco e principais feições e características geoambientais

\begin{tabular}{|c|c|}
\hline Feição Geoecológica & Principais características \\
\hline Faixa de praia/pós-praia & $\begin{array}{l}\text { Superfície arenosa/sedimentar plana a suavemente } \\
\text { ondulada sob efeito direto das ações das marés, faixa de } \\
\text { praia correspondente a zona de espraiamento das marés e } \\
\text { ondas compondo um ambiente extremamente instável, } \\
\text { presença de algas e fauna composta por pequenos moluscos } \\
\text { e crustáceos, além de aves aquáticas, zona de pós-praia de } \\
\text { largura variável com presença de vegetação pioneira } \\
\text { psamófila e fauna correspondente com crustáceos, répteis e } \\
\text { aves migratórias. Utilizada como área de } \\
\text { lazer/balneabilidade, prática de esportes, ancoradouro de } \\
\text { embarcações e barracas de praia. }\end{array}$ \\
\hline Dunas móveis & $\begin{array}{l}\text { Depósitos eólicos arenosos em forma de morros de formação } \\
\text { holocênica de origem continental e retrabalhada pela ação } \\
\text { marinha, solos inconsolidados e relevo ecodinamicamente } \\
\text { instável, vegetação pioneira psamófila incipiente, morfologia } \\
\text { dunar modelada pela ação eólica (velocidade, intensidade e } \\
\text { direção dos ventos, ambiente ocupado por passeios de } \\
\text { bugues, trilhas ecoturísticas e construções residenciais. }\end{array}$ \\
\hline Dunas fixas & $\begin{array}{l}\text { Acumulações de sedimentos arenosos relativamente } \\
\text { bioestabilizados por uma vegetação subperenifólia de dunas, } \\
\text { formação de solos em seu horizonte superior, corresponde a } \\
\text { uma fase serial posterior ao das dunas móveis, efeito de } \\
\text { tosqueamento do vento na vegetação disposto no setor de } \\
\text { barlavento dunar constituição de um lençol freático de nivel } \\
\text { elevado, alta fito e zoodiversidade, práticas de extrativismo } \\
\text { vegetal, construção de residencias, edifícios e condomínios } \\
\text { residenciais fechados, pousadas, hotéis e restaurantes. }\end{array}$ \\
\hline Planície Lacustre & $\begin{array}{l}\text { Correspondem a ambientes de gênese sedimentar argilo- } \\
\text { arenosos de carater fluviolacustre e de cronologia } \\
\text { holocênica, constituem áreas de acumulação inundáveis } \\
\text { compostas por leitro fluviolacustre e terraços de pequena } \\
\text { amplitude altimétrica em suas margens. Tem sua origem } \\
\text { fluviolacustre alimentada pelo lençol freático ou pelo sistema } \\
\text { de escoamento superficial e pluvial. As bordas da planície } \\
\text { fluviolacustre está revestida pela vegetação de várzea e as } \\
\text { formas de uso e ocupação correlacionam-se a cultivos de } \\
\text { subsistência, práticas de esportes nauticos e equipamentos } \\
\text { turísticos como barracas de praia e pequenos restaurantes. }\end{array}$ \\
\hline
\end{tabular}

Fonte: Adaptado de Souza (2000).

A Figura 2 representa a distribuição espacial das unidades e feições geoecológicas da Praia do Cumbuco e seu entorno geográfico imediato. 
Figura 2 - Unidades geoecológicas da Praia do Cumbuco e seu entorno geográfico

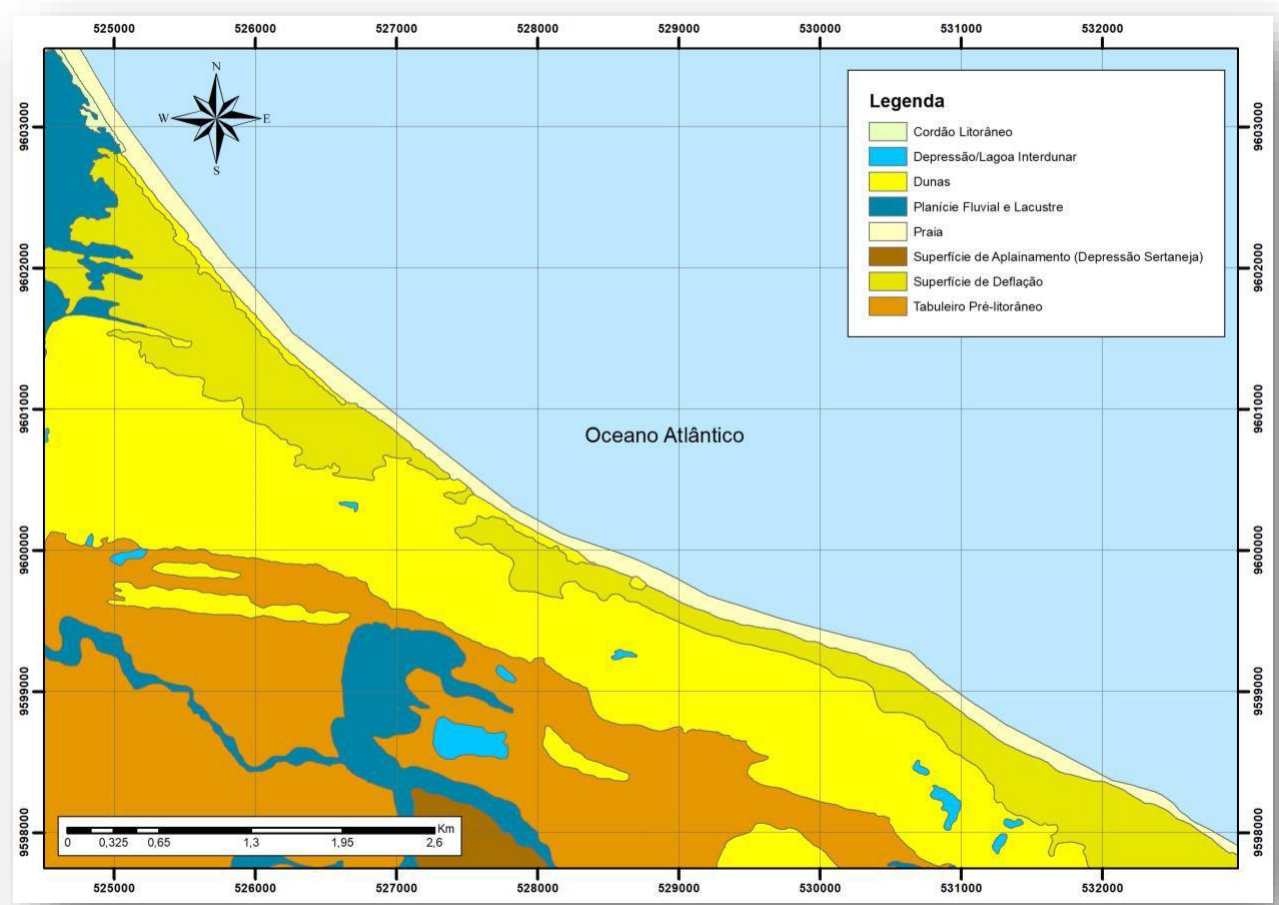

Fonte: Elaborado pelos autores (2018).

A paisagem apresenta uma síntese do ambiente, inclui elementos naturais e elementos culturais, possibilita identificar as consequências e os agentes do turismo em determinado território e se constitui em recurso para o turismo. De modo que se estabelece uma correlação entre a paisagem e o território, denominado território turístico dada a presença de turistas.

A paisagem indica ao turista a desejada mudança de lugar (FONT, 1989 apud PIRES, 2005, p.419) e vai sendo modificada com a implantação de equipamentos para prestação de serviços de lazer e turismo. Esses equipamentos passam a fazer parte das paisagens utilizadas pelo marketing público e privado na atração de turistas, são associados ao valor turístico dos lugares e impactam na qualidade visual dessas paisagens.

\section{PERCURSO METOdológico}

Para identificar a qualidade visual da paisagem para o turismo realizou-se o diagnóstico do litoral de Cumbuco tendo como orientação teórico-metodológica a geoecologia das paisagens, assim identificaram-se as unidades geoecológicas o que permitiu aprofundar o conhecimento tanto sobre o ambiente físico quanto sobre as relações socioespaciais da área. A concepção de paisagem como aquilo que a visão alcança direcionou este estudo, desse modo, a faixa observada centrou-se no que um observador pode captar a olhar posicionando-se na área compreendida entre a zona de estirâncio e a área de pós-praia.

Para identificação da qualidade visual da paisagem para o turismo agregou-se neste estudo interdisciplinar conteúdo da análise de indicadores da qualidade visual elaborada por Pires (2001, 2005). Para este autor essa metodologia desenvolvida para análise da paisagem tendo por base os indicadores de qualidade visual está inserida na área de conhecimento dos estudos da paisagem, particularmente da escola angloamericana.

$\mathrm{Na}$ análise da qualidade visual estabelece-se a definição e registro fotográfico de pontos com o objetivo de captar diferentes elementos ao longo da área (PIRES, 2005, p.420). A área estudada permitiu que 
fossem adotados como parâmetros para definição dos pontos os locais preferenciais ou potenciais de concentração dos turistas e usuários da paisagem e onde estão os atrativos turísticos. A partir da observação da área foram incluídos pontos representativos do trecho, seguindo-se o seguinte caminho metodológico: identificação das unidades geoecológicas da área, registro de fotos representativas e aplicação de critérios dos indicadores.

Para realizar essa avaliação Pires (2005), definiu os seguintes indicadores: diversidade, naturalidade, singularidade e detratores. Esses indicadores permitem o levantamento do valor intrínseco das paisagens e da ação da sociedade. A diversidade é um indicador que expressa a variedade paisagística existente em um determinado território. Assim a paisagem variada assume mais valor que uma paisagem homogênea, pois apresenta partes diferenciadas com distintos componentes visuais (PIRES, 2005). A Quadro 2 apresenta os componentes desse indicador.

Quadro 2 - Diversidade visual e escala de classificação da paisagem

\begin{tabular}{|c|c|c|c|c|c|}
\hline \multirow[b]{2}{*}{ COMPONENTES } & \multirow{2}{*}{$\begin{array}{c}\text { ELEMENTOS } \\
\text { VISUAIS } \\
\text { (propriedades } \\
\text { visuais) }\end{array}$} & \multicolumn{4}{|c|}{ NÍVEL DE DESTAQUE } \\
\hline & & $\begin{array}{l}\text { GRANDE } \\
\text { (PESO 6) }\end{array}$ & $\begin{array}{l}\text { MODERADO } \\
\text { (PESO 3) }\end{array}$ & $\begin{array}{l}\text { POUCO } \\
\text { (PESO I) }\end{array}$ & $\begin{array}{l}\text { NENHUM } \\
\text { (PESO 0) }\end{array}$ \\
\hline \multirow{2}{*}{ RELEVO } & Forma/Volume & & & & \\
\hline & Linha & & & & \\
\hline \multirow{3}{*}{ VEGETAÇÃO } & Textura & & & & \\
\hline & Cor/Tonalidade & & & & \\
\hline & Forma & & & & \\
\hline \multirow{2}{*}{ ÁGUA } & Cor/Tonalidade & & & & \\
\hline & Linha/Forma & & & & \\
\hline \multirow{3}{*}{$\begin{array}{l}\text { ATIVIDADES } \\
\text { HUMANAS }\end{array}$} & Forma & & & & \\
\hline & Cor & & & & \\
\hline & Linha & & & & \\
\hline \multicolumn{6}{|c|}{\begin{tabular}{c|c} 
SUB-TOTAL & \\
$\left(\mathrm{N}^{\circ}\right.$ DE OCORRÊNCIA X PESO $)$ & \\
\end{tabular}} \\
\hline \multirow{3}{*}{$\begin{array}{l}\text { ESCALA DE } \\
\text { CLASSIFICAÇÃO }\end{array}$} & \multicolumn{2}{|c|}{ DE 31 A 60 - Alta Diversidade } & \multirow{2}{*}{\multicolumn{3}{|c|}{ CLASSIFICAÇÃO }} \\
\hline & \multicolumn{2}{|c|}{ DE 11 A 30 - Média Diversidade } & & & \\
\hline & \multicolumn{2}{|c|}{ ATÉ 10 - Baixa Diversidade } & & & \\
\hline
\end{tabular}

Fonte: Pires (2005).

No caso da naturalidade, essa expressa a ausência ou insignificância de elementos ou estruturas de origem humana em uma área. É representada, pela vegetação natural, resultante de processo interativo entre os fatores do meio físico. A vegetação, quando remanescente de formações originais com pouca ou nenhuma alteração, representa o mais alto grau de equilíbrio ecológico do ambiente em que se encontra, merecendo elevada valorização pelo aspecto de naturalidade que empresta à paisagem (PIRES, 2005). O Quadro 3 detalha os itens desse indicador. 
Quadro 3 - Classificação de diferentes gradientes de modificação da paisagem natural

\begin{tabular}{|l|c|}
\hline \multicolumn{1}{|c|}{ GRADIENTE DE MODIFICAÇÃO DA PAISAGEM NATURAL } & CLASSIFICAÇÃO \\
\hline Paisagem natural sem alterações visíveis. Paisagem natural pouco alterada. & NATURALIDADE SUPERIOR (S) \\
\hline Paisagem predominantemente natural com alterações & NATURALIDADE MÉDIA- \\
\hline pequenas a moderadas. & SUPRIOR (MS) \\
\hline $\begin{array}{l}\text { Paisagem tipicamente rural (campestre, cultivada, colonial). } \\
\text { Paisagem urbana/peri-urbana com entorno predominantemente natural. }\end{array}$ & NATULIDADE (M) \\
\hline $\begin{array}{l}\text { Paisagem peri-urbana misturada com elementos da paisagem rural. } \\
\text { Paisagem urbana/peri-urbana com presença de elementos naturais em seu entorno. } \\
\text { Paisagem urbana com expressiva presença de áreas verdes (arborização de rua, bos- } \\
\text { ques, parques/praças). }\end{array}$ & NATURALIDADE MÉDIA-INFE- \\
\hline Paisagem urbana com poucos elementos naturais ou áreas verdes. & RATURALIDADE INFERIOR (I) \\
\hline
\end{tabular}

Fonte: Pires (2005).

A singularidade denota as ocorrências de origem natural como feições geomorfológicas, elementos vegetais, espécies animais, sítios paleontológicos ou manifestações de origem humana a exemplo de sítios arqueológicos e usos do solo, assim como elementos visuais, como unicidade, unidade, raridade, antiguidade, grandiosidade, excepcionalidade, beleza, amplitude visual, interesse histórico e outras características notáveis que as tornam singulares (PIRES, 2005).

Pires (2005) definiu para o indicador de singularidade critérios de identificação e de classificação. Os critérios de classificação são: grande potencial de atratividade turística em nível nacional e internacional (Gr), razoável potencial de atratividade turística em nível estadual e sub-nacional (Rz) e limitado potencial de atratividade turística em nível sub-estadual (regional) $(\mathrm{Lm})$. Os indicadores detratores, por sua vez, indicam atividades humanas que imprimem um aspecto de artificialização e distanciamento das condições naturais da paisagem e, muitas vezes, de sua degradação visual e ambiental. Processos naturais tais como atividades vulcânicas, erosão, sedimentação, maremotos, tufões, entre outros, também atuam na detração da qualidade visual e, muitas vezes, têm seus efeitos negativos potencializados pelas atividades humanas.

Quando o levantamento for sobre atividades humanas que proporcionam aumento da qualidade visual de uma paisagem, devem ser consideradas nos indicadores diversidade e singularidade (PIRES, 2005). Os critérios de classificação dos indicadores detratores são: pequena intrusão (PI), conjunto de pequenas intrusões (Cj-PI), média intrusão (MI), conjunto de médias intrusões (Cj-MI), grande intrusão (GI) e conjunto de grandes intrusões (Cj-GI). Esses indicadores são sintetizados no quadro geral que agrega todos os elementos visuais estudados, conforme apresenta o Quadro 4.

Quadro 4 - Grade final de avaliação da qualidade visual da paisagem

CLASSE DE QUALIDADE VISUAL

QUALIDADE VISUAL SUPERIOR (S)

QUALIDADE VISUAL MÉDIA-SUPERIOR (MS)

QUALIDADE VISUAL MÉDIA (M)

QUALIDADE VISUAL MÉDIA-INFERIOR (M I)

\section{PARÂMETROS DE ENQUADRAMENTO}

A) Nivcis superiores de diversidade e de naturalidade

B) Com singularidade grande a razoável

C) Ausência de detratores ou. no máximo, pequeno detrator

A) Nível superior de diversidade e médio-

superior de naturalidade

B) Com singularidade limitada a razoável

C) Ausência de detratores ou, no máximo, pequenos detratores

A) Níveis médios de diversidade e de naturalidade

B) Ausência de singularidades

C) Presença de pequenos a médios detratores

A) Média diversidade

B) Naturalidade média -inferior

C) Ausência de singularidade

Fonte: Lopes (2005).

Os pontos registrados são representativos do trecho estudado e contribuem para apreender a 
qualidade visual da praia do Cumbuco por meio do estudo da paisagem entendida como síntese ambiental (PIRES, 2005). A partir das adaptações da metodologia foi realizada uma avaliação do trecho estudado.

\section{RESULTADOS E DISCUSSÕES SOBRE A ANÁLISE DA QUALIDADE VI- SUAL DO CUMBUCO}

$\mathrm{Na}$ análise da qualidade visual das paisagens da praia do Cumbuco foram escolhidos sete (7) pontos representativos da área. A Figura 3 apresenta o registro fotográfico desses pontos. A variedade de elementos naturais conferiu diversidade média às paisagens de Cumbuco significando que a paisagem é mais homogênea do que heterogênea. As fotos apresentam os componentes do indicador diversidade: relevo, vegetação, água e atividades humanas. A presença das jangadas (figura 3) expressa a resistência da atividade tradicional da pesca que se mantém no contexto de mudanças socioculturais do lugar, inclusive com a participação dos jangadeiros oferecendo passeios para turistas nessas embarcações tradicionais.

A naturalidade também foi qualificada como média. Esse componente é menor na área de maior concentração de turistas, o que ocorre, principalmente, na faixa que corresponde à vila do Cumbuco, pois a paisagem foi bastante alterada. Destacam-se na naturalidade das paisagens analisadas, o mar, o céu e a vista panorâmica que valorizam a área. A foto do ponto 7, considerado superior, representa as áreas na faixa de pós-praia que foram menos modificadas. A naturalidade é um indicador da conservação da paisagem e está diretamente relacionada ao equilíbrio dos sistemas ambientais. Contudo, no ponto mencionado não se trata de vegetação natural, mas da insignificância quantitativa de intervenções da sociedade.

Figura 3 - Registro Fotográfico dos Pontos Turísticos

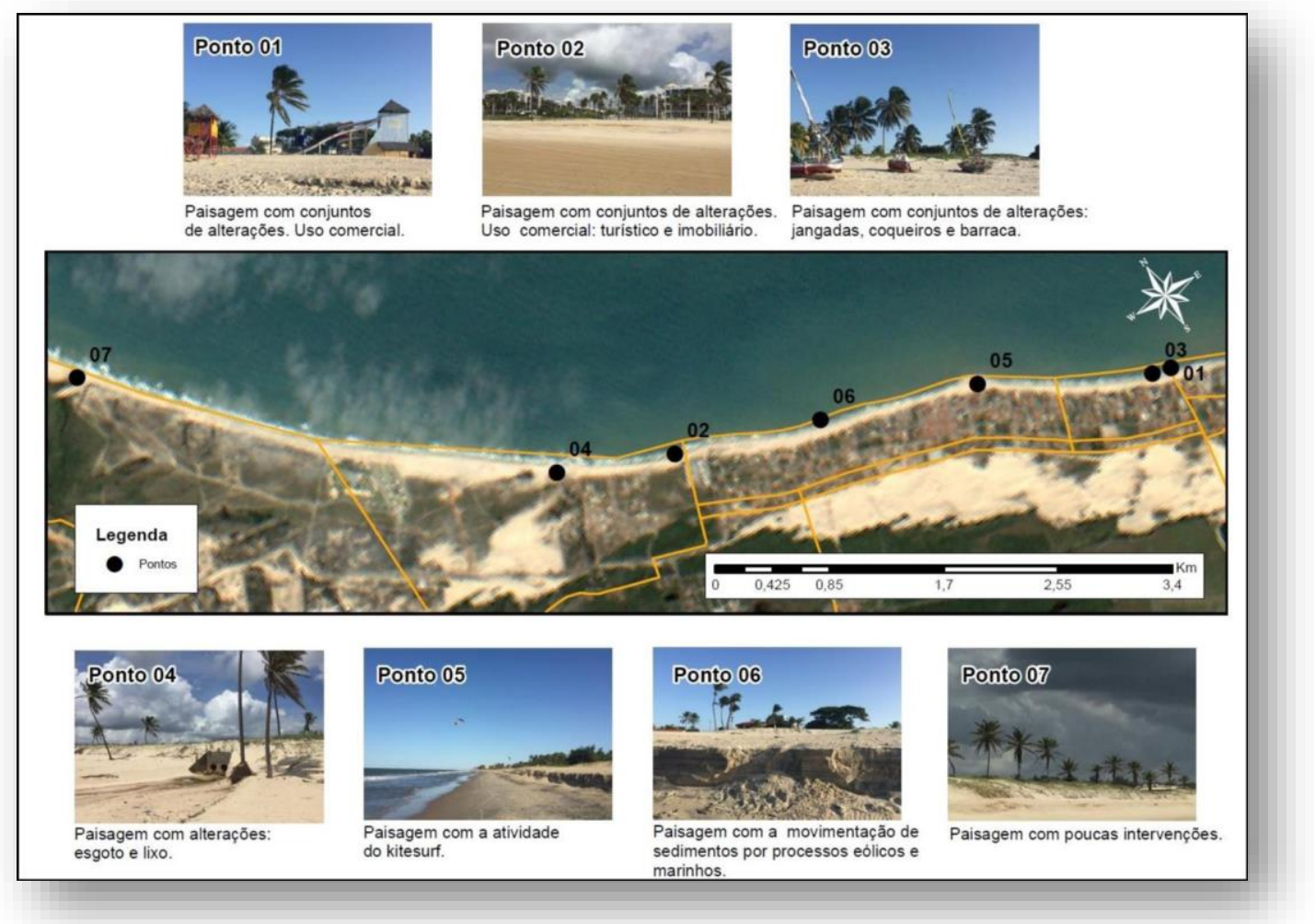

Fonte: Elaborado pelos autores (2018).

No que se refere aos indicadores detratores, verificou-se Qualidade Média Inferior (QMI) e Qualidade Visual Média (QVM), influência dos conjuntos de grandes intrusões (Cj-GI), pois esse indicador revela 
o aspecto artificializado de partes do trecho estudado. A presença de médios e grandes indicadores detratores, como as casas de veraneio, barracas, restaurantes, hotéis e condomínios, conforme as cenas 1, 2, 3 e 4, por exemplo, acarretou a qualidade visual inferior.

Esses detratores registram diferentes momentos do processo histórico de ocupação da área e interferem na qualidade visual. A foto do ponto 4 apresenta a saída de esgoto resultante direto da ação da sociedade no ambiente. $\mathrm{Na}$ foto do ponto 6 , registra-se a movimentação de sedimentos por processos eólicos e marinhos que afeta a paisagem da área. Processos resultantes da ação da natureza com interferência da ação da sociedade.

O ponto 7 representa áreas sem intrusão ou com pouca intrusão. Nesse trecho dois investimentos aproveitam o potencial natural, pois são poucas as intervenções e isso os valoriza. A presença dos detratores ocasionou perda de naturalidade. Saliente-se que as residências, construções imobiliárias e hotéis na faixa de pós-praia possuem diferentes padrões, algumas construções se integram mais à paisagem do lugar e outras não. Apesar da presença das barracas, restaurantes e hotéis, não há barreiras físicas para a circulação de pessoas, mas uma territorialização concentrada. A grade final de avaliação da qualidade visual da paisagem apresenta os resultados dos indicadores, conforme Quadro 2:

Quadro 2 - Análise da qualidade visual das paisagens

\begin{tabular}{|c|c|c|c|c|}
\hline Ponto & Diversidade & Naturalidade & Detratores & $\begin{array}{c}\text { Qualidade } \\
\text { visual }\end{array}$ \\
\hline 1 & Média & Média & Cj Gi & Média inferior \\
\hline 2 & Média & Média & Cj Gi & Média inferior \\
\hline 3 & Média & Média & MI & Média \\
\hline 4 & Média & Média & Cj Gi & Média \\
\hline 5 & Média & Média & \\
\hline
\end{tabular}

Fonte: Elaborado pelos autores, 2018.

A análise dos indicadores diversidade, naturalidade e detratores resultou na qualidade visual final média para cinco pontos e média inferior para três pontos. Sobre o indicador singularidade, a classificação estabelece: grande potencial de atratividade turística em nível nacional e internacional (Gr), razoável potencial de atratividade turística em nível estadual e sub-nacional (Rz) e limitado potencial de atratividade turística em nível sub-estadual (regional) (Lm) (PIRES, 2005).

Desse modo, ao considerar que o lugar, além da beleza cênica apresenta condições de vento ideais para a prática do kite surf e atrai praticantes de vários países, além dos turistas nacionais e internacionais para o turismo de sol e praia conferiu-se singularidade (Gr). A área. Dessa forma, a qualidade visual da praia do Cumbuco é média, no entanto, do ponto de vista da singularidade apresenta classificação superior.

\section{CONCIDERAÇÕES FINAIS}

A paisagem é elemento relevante para a prática do turismo e esta pesquisa permitiu demonstrar a contradição entre essa premissa e as transformações dos lugares pelo e para o turismo. As atividades de lazer e turismo tornaram-se importantes economicamente para a praia do Cumbuco, mas trouxeram vários impactos. De modo que com o desenvolvimento do turismo verificou-se uma relação contraditória entre turismo e paisagem, haja vista que essa, motivadora dos fluxos turísticos, transformou-se perdendo características próprias e adquirindo novas feições devido à utilização dos lugares para e pelo turismo.

A linha de costa do Cumbuco encontra-se em boa parte ocupada por equipamentos urbanos e turísticos que comprometem a estabilidade dos ambientes e por conseguinte, os serviços ecossistêmicos. Identificaram-se, no entanto, alguns trechos mais conservados e com pouca quantidade de intrusões.

A prática do turismo ensejou a formação de novas práticas e significados, produzindo espacialidades diferentes do cotidiano do lugar e alterando as paisagens. Assim o turismo se concretiza geograficamente, interfere nos territórios apresentando significados específicos e diversos daqueles que caracterizam as 
espacialidades produzidas pela vida cotidiana anterior.

Essa realidade foi captada na análise da paisagem da praia do Cumbuco que conferiu qualidade visual média na análise dos indicadores diversidade, naturalidade e detratores. Na classificação do indicador singularidade a qualidade superior foi verificada pelo fato da praia do Cumbuco ser núcleo receptor de turistas nacionais e internacionais. Dessa forma, apesar das intervenções nas paisagens de Cumbuco, essas ainda possuem beleza cênica. Assim, apesar do distanciamento das condições naturais da paisagem, da ocupação da faixa de pós-praia e deslocamento dos sedimentos dunares, algumas áreas apresentam pouca intrusão, e por conseguinte, a qualidade visual da paisagem é superior. A ocupação humana é menos densa entre o fim da vila do Cumbuco e a margem direita do rio Cauípe suavizando a densa ocupação de outros trechos e influenciando na avaliação geral da área. Identifica-se assim a necessidade de ações que resguardem e orientem o futuro dessas áreas.

Verificou-se a necessidade de ordenamento do uso da faixa de praia delimitando a área para banhistas e a prática do kitesurf. E ainda para o uso de quadriciclos que pode acarretar aumento dos processos erosivos e mudanças na morfologia da área de pós-praia. Essa faixa de pós-praia e as dunas móveis são ambientes fortemente instáveis e com alta vulnerabilidade à ocupação.

A geoecologia da paisagem permitiu levantar e analisar as unidades geoecológicas da área e a utilização dos indicadores para análise da qualidade visual das paisagens turísticas permitiu averiguar a diversidade, naturalidade, singularidade e ainda os elementos detratores da paisagem do Cumbuco.

A proximidade de Fortaleza e a beleza paisagística contribuem para que a praia do Cumbuco seja um dos destinos mais procurados do litoral cearense. Os elementos paisagísticos naturais e culturais contribuem na qualidade visual da área e apontam para a necessidade de se cuidar dessas paisagens por meio do ordenamento do uso da área, orientação para a prática do turismo tendo em vista o planejamento integrado da praia do Cumbuco na busca da sustentabilidade ambiental, social e econômica.

\section{REFERÊNCIAS}

ARAÚJO, Enos Feitosa. PEREIRA, Alexandre Queiroz. O turismo e a valorização do litoral metropolitano: espacialidade turística em Caucaia-CE. RA É GA. V 21 p. 78-104. 2011.

CRUZ, Rita de Cássia Ariza. As paisagens artificiais criadas pelo turismo. In: YÁZIGI, Eduardo (org.). Turismo e Paisagem. São Paulo: Contexto, 2002.

INSTITUTO BRASILEIRO DE GEOGRAFIA E ESTATÍSTICA (IBGE). Disponível em http://www. ibge.gov.br/ Acesso em: 12 ago. 2019.

INSTITUTO DE PESQUISA E ESTRATÉGIA ECONÔMICA DO CEARÁ (IPECE). Perfil Básico Municipal de Caucaia. 2017. Disponível em: http://www.ipece.ce.gov.br/perfil_basico_municipal/2017/Caucaia.pdf. Acesso em: 12 maio 2018.

PIRES, Paulo Santos. O potencial turístico dos recursos naturais. In: Suporte teórico para a disciplina Bases Ecológicas e Ambientalistas do Turismo. Apostila. Balneário Camboriú: Curso de Mestrado em Turismo e Hotelaria. CEBC. UNIVALI. 2001. Tópico 2. 41p.

. A análise de indicadores da qualidade visual como etapa da caracterização de paisagens turísticas: uma aplicação no distrito-sede de Porto Belo-SC. Turismo: visão e ação. Balneário Camburiú, vol.7-n.3 p.417-426 set./dez.2005.

PREFEITURA MUNICIPAL DE CAUCAIA (PMC). O Turismo. Disponível em: https://www.caucaia.ce.gov.br/index.php?tabela $=$ pagina\&acao $=$ pagina\&codigo=30. Acesso em: 02 maio 2018.

RODRÍGUEZ, José Manuel Mateo; SILVA, Edson Vicente da; LEAL, Antonio Cezar. Planejamento Ambiental em Bacias Hidrográficas. In: SILVA, Edson Vicente da; RODRÍGUEZ, José Manuel Mateo; MEIRELES, Antônio Jeovah de Andrade (Org.). Planejamento Ambiental e Bacias Hidrográficas. Fortaleza: Edições UFC, 2011.

SOUZA, Eudes André Leopoldo. Metropolização litorânea: produção do espaço do lazer e mercado 
imobiliário 262f. Dissertação (Mestrado Acadêmico em Geografia). Programa de Pós-Graduação em Geografia, Universidade Estadual do Ceará, Centro de Ciências e Tecnologia, Curso de Mestrado Acadêmico em Geografia. Fortaleza, 2013. 